\title{
LA HACIENDA PÚBLICA FILIPINA HACE UN SIGLO: EN TORNO A LOS PROBLEMAS FINANCIEROS EN LA COLONIA ORIENTAL DURANTE LA GUERRA (1896-1898)*
}

POR

\author{
INÉS ROLDÁN DE MONTAUD
}

CSIC/ Universidad de Alcalá

Después de presentar un breve panorama de la situación de las finanzas filipinas en vísperas de la guerra que se inicia en 1896, en el artículo se estudian los medios financieros que los gobiernos metropolitanos fueron arbitrando para hacer frente a las exigencias extraordinarias ocasionadas por la misma. Se dedica especial atención a los problemas monetarios del archipiélago así como a la operación de crédito realizada en 1897 que daba origen al nacimiento de la deuda del Tesoro de Filipinas. Finalmente, se dedican algunas páginas a estudiar la suerte de esta deuda tras la firma del Tratado de París.

\section{LA HACIENDA FILIPINA EN VISPERAS DE LA GUERRA}

A fines de agosto de 1896 se producía un estallido revolucionario en Filipinas. A comienzos del año anterior se había organizado en Madrid un movimiento cuyo objeto había sido lograr una vez más la representación parlamentaria para las islas Filipinas, excluidas del régimen constitucional español como Cuba o Puerto Rico en 1836. Haciéndose eco de aquel movimiento un diputado catalán, Emilio Junoy, presentaba un proyecto de ley requiriendo la representación parlamentaria para las Filipinas. La colonia filipina en España había realizado durante años una extensa e infructuosa propaganda para 0890

* Este trabajo forma parte de la investigación financiada por la DGES PB96- 
difundir sus aspiraciones y lograr ciertas reformas: Graciano López, Del Pilar, Antonio Luna, López Seña desde las páginas de la Solidaridad, y el propio Rizal no eran sino algunos de los nombres unidos a semejante empresa ${ }^{1}$.

Tras años de fracaso se había constituido en Filipinas el Katipunam, una organización revolucionaria que abandonó los medios legales alzándose en la provincia de Cavite ${ }^{2}$. Tras lo que parecía a la opinión un fracaso del general Blanco y Erenas, duramente contestado por su política, pocos meses más tarde llegaba de la península el general Polavieja con nuevas tropas. De inmediato se planteaba como en el caso de Cuba, donde en marzo del año anterior se había iniciado un levantamiento independentista, el problema de los recursos financieros para hacer frente a los gastos extraordinarios que produciría la represión de aquellos movimientos contra la soberanía española.

En estas páginas se realiza una primera aproximación a algunos problemas financieros relacionados con la guerra de Filipinas: de dónde se obtuvieron los recursos para pagarla, es decir cuáles fueron los instrumentos financieros utilizados. Para ello se han utilizado básicamente las Cuentas de la Campaña de Filipinas que fueron publicadas en la Gaceta de Madrid en cumplimiento de una real orden de octubre de 1898, así como la correspondencia del agente de la Banca Rothschild en Madrid, Ignacio Baüer, y algunas colecciones de prensa de la época, entre otras fuentes. Se trata de una primera y provisional aproximación en tanto se disponga de documentación esencial como las liquidaciones presupuestarias y las cuentas corrientes del Tesoro Filipino con la Cuenta de la Campaña de Filipinas.

Una vez más, como en el caso de Cuba, la metrópoli decidía que los gastos que ocasionase la represión del movimiento insurreccional serían responsabilidad exclusiva del Tesoro de las islas Filipinas, independiente del metropolitano, y como los de Cuba y Puerto Rico con sus recursos y obligaciones propias. Al iniciarse la insurrección en Cuba, las Cortes españolas se habían apresurado a aprobar los

\footnotetext{
1 Anteriormente Calvo Muñoz había presentado una enmienda al artículo 25 de la ley de sufragio universal exigiendo que se restableciese a Filipinas su derecho parlamentario, véase Filipinas en las Cortes. Discursos pronunciados en el Congreso de los Diputados sobre la representación parlamentaria del Archipiélago Filipino, Madrid, Imprenta de Enrique Jaramillo, 1890, pp. 17 y ss. 1936, p. 51 .

2 R. MuÑIZ LAVAlle, Filipinas y la guerra del Pacífico, Madrid, Bolaños y Aguilar,

R. I., 1998, n. $^{\circ} 213$
} 
créditos para hacer frente a los gastos. En marzo de 1895 autorizaron un crédito extraordinario de campaña con cargo a las partidas de Guerra y de Marina del presupuesto de Cuba.

En vísperas de la guerra la Hacienda cubana se hallaba completamente endeudada. Desde hacía años los ingresos realizados en la Gran Antilla habían sido insuficientes para hacer frente a los gastos, y año tras año iban saldando los presupuestos con un déficit, que alimentaba una deuda en constante crecimiento, cuyo servicio consumía la mitad de los ingresos. El crédito del Tesoro cubano que no era capaz de hacer frente a sus obligaciones ordinarias era dudoso. Y si inicialmente el crédito extraordinario de campaña se alimentó mediante la colocación de deuda del Tesoro de Cuba, llegado el otoño de 1896 la metrópli tuvo que obtener con rentas propias los recursos consumidos por la guerra, que fueron entregados al Tesoro de Cuba en calidad de anticipo ${ }^{3}$.

El caso filipino era distinto. El archipiélago del Pacífico entraba en la guerra sin deuda pública y con una Hacienda relativamente saneada. Sobre sus aduanas - que proporcionaban más de seis millones de pesos de los 17 en que se calculaban los ingresos en el presupuesto para el ejercicio 1896-97- no pesaba obligación o hipoteca alguna. Desde el inicio de los noventa las rentas públicas habían ido experimentando —al compás del crecimiento económico del archipiélago - un importante desarrollo. Los ingresos presupuestados habían pasado de 11 millones de pesos en 1884-85 a 17 en el

3 Sobre la financiación de la guerra en Cuba pueden consultarse: "El Banco de España (1874-1914): Un Banco nacional", en Gabriel TORTELla y Pedro SwHwARTZ (eds.) La Banca Española en la Restauración. Política y finanzas, Madrid, Banco de España, 1974. Rafael ANES y Pedro TEDDE DE LORCA "La deuda pública y el Banco de España (18741900)", Hacienda Pública Española, núm. 18, 1976, pp. 35-50. El problema de la financiación de la guerra ha sido abordado por Elena HERNÁNDEZ SANDOICA y María Fernanda MANCEBO "La burguesía valenciana y su participación en la financiación de la guerra de Cuba y Puerto Rico", Estudis D'Historia Contemporania del Pais Valencia, 1979, núm. 1, pp. 355-401, y "El empréstito de 1896 y la política financiera en la guerra de Cuba", Cuadernos de Historia Moderna y Contemporánea, 1980, pp. 157-168 y por Jordi MALUQUER DE MOTES en "La financiación de la Guerra de Cuba y sus consecuencias sobre la economía española. La deuda pública", en Consuelo NARANJo, Miguel Angel PUIG-SAMPER y Luis Miguel García Mora (eds.), La Nación Soñada: Cuba, Puerto Rico y Filipinas ante el 98, Aranjuez, Doce Calles, 1996, pp. 317-329. Puede consultarse también Joseph HARRISON, "Financial Reconstruction in Spain after the Loss of the Last Colonies", Journal of European Economic History, vol. 9, núm. 2, 1980, pp. 317-349. Inés ROLDAN DE MONTAUD, "Guerra y finanzas en la crisis de fin de siglo: 1895-1900", Hispania, LVII/2, núm. 196, 1997, pp. 611-675.

R.I., $1998, \mathrm{n}^{\circ} 213$ 
presupuesto vigente al estallar la insurrección. Si tomamos los ingresos presupuestados en Cuba para los ejercicios 1883-84 y 189394 encontramos, por el contrario, una caída de las rentas de 34 millones a 26. Ese año el presupuesto cubano saldaba con un déficit de 5.4 millones de pesos, un 26 por 100 de los ingresos previstos. Con todo, los ingresos presupuestados para las islas Filipinas (generales y locales) representaban 2.2 pesos por habitante, en tanto que en la península se pagaban once en concepto de gastos generales y seis por gastos provinciales y municipales, en Cuba excedían dicha ci$\mathrm{fra}^{4}$. Indudablemente, las Filipinas no eran ricas, pero diversos índices indican que en aquellos lustros de finales de siglo experimentaban una etapa de crecimiento. Los testimonios y las estadísticas así lo confirman.

Avanzado el mes de junio de 1896 el Noticiero Universal recogía unas declaraciones del general González Parrando, buen conocedor de Filipinas por sus prolongadas estancias en aquellas tierras. Las Filipinas estaban en un estado desahogado, carecían de deuda, la riqueza aumentaba cada año y los presupuestos saldaban con superávit, indicaba el general. Un punto oscuro ensombrecía la situación: el problema de los cambios, cuyo origen estaba en la carencia de un sistema monetario y en la circulación de moneda de plata mexicana y de moneda fraccionaria 5 . El problema monetario si bien no impedía el crecimiento, sí estaba ocasionando graves dificultades que contribuían a ralentizarlo. En cualquier caso, en vísperas de la insurrección parecía haberse abandonado ya el pesimismo que apenas una veintena de años atrás expresaban estas líneas de Gabino Pérez Valdés:

"Una colonia que no se sostiene por sus propios recursos; que no puede sin recurrir al crédito cubrir sus compromisos; que no puede imponer impuestos para levantar el crédito porque no hay riqueza bastante para ser imponible en la escala que sería necesario para hacerla productiva, que tiene comercio insignificante con la península y que a cambio de los gastos sólo le reporta el interés de una poca cantidad de

\footnotetext{
4 Camilo Millan y Villanueva El gran problema de las reformas en filipinas planteado por el Español periódico diario de Manila y redactado por Don Camilo Millán y Villanueva consejero ponente de administración y exgobernador civil de varias provincias del archipiélago, Manila, Imprenta de J. Lafont, 1897.

5 Abogaba por la recogida de la plata mexicana y el establecimiento del patrón oro, El Comercio, 23 de julio de 1896.
}

R. I., $1998, \mathrm{n}^{\circ} 213$ 
tabaco, y pequeñas sumas que paga por cuenta de sus gastos en China, presenta desde luego la disyuntiva de su abandono o completa reforma"6.

\section{EL INICIO DE LA INSURRECCION: PRIMERAS MEDIDAS FINANCIERAS.}

La situación de la Hacienda filipina era pues desahogada en vísperas del estallido revolucionario y las cuentas cerraban satisfactoriamente libres de la existencia de deuda externa ${ }^{7}$. El envío de tropas para aplastar la insurrección iba a exigir recursos extraordinarios que no podían correr a cargo del presupuesto ordinario. Conocido el alzamiento de los tagalos en Luzón, se había producido un movimiento espontáneo de donativos, suscripciones, así como la creación de cuerpos de milicias voluntarias, cuyos equipos eran costeados por los propios voluntarios o eran objeto de donación por parte de diversas instituciones ${ }^{8}$. Por ejemplo el Banco Español de Filipinas se ocupó de los gastos de un cierto número de voluntarios, haciendo otro tanto el Casino Español de Manila, que poco después donaba además un tren sanitario. El arzobispo de Manila ponía a disposición del comandante del cuerpo de voluntarios la cantidad que fuese necesaria para equipar 10 voluntarios, el marqués de Peña Plata entregaba 1.000 pesos para que se invirtieran igualmente en la vestimenta y equipo de voluntarios que no pudiesen procurárselos, y Julián Andrés del pueblo de Navolas hacía entrega de "tres cuarterolas de

6 Situación económica de Filipinas y medios para mejorarla, por Gabino Pérez Valdés, Madrid, Andrés Orejas, p. 27.

7 Esto no quiere decir que no existiera deuda local. El 6 de abril de 1877 el gobierno insular dispuso la creación de una emisión de títulos del Tesoro por importe de 3.333.909 pesos para saldar los créditos pendientes por las cosechas de tabaco de 1875,1876 y parte de la correspondiente a 1874. La operación fue sancionada por Real decreto de 28 de marzo de 1878. Esos títulos se canjearon por las papeletas que representaban dichos créditos y que se habían ido entregando a los cosecheros y fueron admitidos por todo su valor para el pago de los débitos devengados a partir de 31 de diciembre por los cosecheros, de los tributos de naturales y mestizos y en fianzas para contratos de servicios públicos. En el presupuesto para el ejercicio 1878-79 se notaba un aumento en la partida de la deuda para hacer frente a esta obligación, y en los presupuestos posteriores se consignaba una cantidad para el pago de los intereses y amortización de esta deuda del Tesoro filipino, que fue disminuyendo a medida que progresaba la amortización de los valores. Presupuesto general para el año 1878-1879, pp. 6 y 93 y Boletín Oficial del Ministerio de Ultramar, año 1877, p. 93.

8 Fenómeno similar al ocurrido en Cuba durante la primera guerra de independencia y del cual nos ocupamos en Inés ROLDÁN DE MONTAUD, La Unión Constitucional y la política colonial de España en Cuba (1868-1898), Madrid, Universidad Complutense, 1991, pp. 46-64. 
tinto de Valdepeñas, cinco arrobas de garbanzos, cinco arrobas de alubias y doce latas de chorizos, para repartirlos entre los artilleros". Las páginas del Diario de Manila o El Comercio, otro de los grandes diarios de Manila, a lo largo de los meses de septiembre y octubre se hacían eco de estas espontáneas generosidades, óbolos casi simbólicos, en cualquier caso insuficientes e inadecuados como medio financiero de amplio alcance. Desconocemos la eficacia como mecanismo financiero del embargo decretado sobre los bienes de los complicados en la insurrección cuyos frutos y rentas debían aplicarse a los gastos extraordinarios ${ }^{10}$.

Ante la imposibilidad de que los gastos excepcionales corriesen a cargo de los presupuestos ordinarios, el gobierno se apresuró a tomar decisiones. A diferencia de lo que ocurría en Cuba y Puerto Rico, consideradas provincias españolas donde regía la Constitución, las posesiones del Pacífico de naturaleza colonial eran ajenas al entramado constitucional. Alli era posible actuar gubernativamente al margen de las Cortes que ni siquiera entendían en la aprobación de la Cuenta General del Estado en el archipiélago ${ }^{11}$. Sin necesidad de intervención de las Cortes, la Real orden de 31 de agosto dispuso que los gastos de organización, transporte y sostenimiento de un batallón de infantería y otro de infantería de marina cuyo envío a Filipinas se preparaba se aplicasen provisionalmente a un capítulo adicional a las secciones 4 y 6, Guerra y Marina, del presupuesto general de Filipinas, sin perjuicio de la concesión definitiva de los créditos correspondientes por los medios establecidos en la legislación vigente. Poco después se preparaba la salida de dos cruceros de la marina de guerra y el envío de más fuerzas del ejército y la escuadra ${ }^{12}$. Tras una consulta al pleno del Consejo de Esta-

9 El Comercio, 14 de septiembre de 1896.

10 Decreto del general Blanco sobre embargos en Gaceta de Manila, 21 de septiembre de 1896. Nada se ha publicado sobre el problema de los embargos durante la guerra de Filipinas, pese a que dio lugar a acalorados discursos en las Cortes. Sobre la problemática en torno a los embargos en la primera guerra de Cuba véase Inés ROLDÁN DE MONTAUD, $L a$ Hacienda en Cuba durante al guerra de los Diez Años (1868-1880), Madrid, Instituto de Estudios Fiscales, 1990, capítulo III, pp. 69-85.

11 Sobre este problema, Julia RUANo CELdRAN, Instituciones Hispano Filipinas del siglo XIX, Madrid, Mafre, 1994, pp. 177-186

12 Manuel SASTRON, La insurrección en Filipinas y guerra hispano americana en el archipiélago 1896-99 Madrid, Sucesora de Minuesa, 1901, p. 78, para información detallada sobre los movimientos de tropas hacia Filipinas en aquel otoño de 1896.

R.I., 1998, n. ${ }^{\circ} 213$ 
do, el Real decreto de 18 de septiembre autorizaba la apertura de un crédito con cargo a las secciones de Guerra y Marina del presupuesto vigente por la cantidad a que ascendiesen las obligaciones que se reconocieran y liquidaran para los servicios de carácter extraordinario e imprevisto que originase el restablecimiento del orden público. Su importe se cubriría provisionalmente con deuda flotante del Tesoro de Filipinas en caso de ser los sobrantes del presupuesto insuficientes ${ }^{13}$.

La Real orden de 12 de diciembre establecía ciertas instrucciones para el cumplimiento de la anterior. Por ejemplo, se insistía en la necesidad de que las oficinas ordenadoras e interventoras en Filipinas establecieran la debida separación entre los gastos públicos imputables a los créditos ordinarios del presupuesto y los que debían ser cargo del extraordinario autorizado para las operaciones de campaña. Las dependencias de Hacienda formarían y remitirían al ministerio mensualmente una cuenta que comprendiera en el cargo las cantidades recibidas por las cajas del Tesoro en Filipinas con destino a los gastos de campaña, detallando por separado las que correspondiesen a los ingresos reales de fondos por préstamos, remesas de caudales, giros, reintegros o cualquier otro concepto y las que sólo representasen formalización de obligaciones satisfechas por la caja del Ministerio de Ultramar. En la data figurarían los pagos ejecutados con aplicación al crédito extraordinario clasificándolos en las subdivisiones que correspondiesen en el presupuesto en vigor a las secciones de Guerra y de Marina, expresando por separado los pagos que se efectuasen por obligaciones de carácter civil imputable al crédito extraordinario así como las anticipaciones que en algún caso se verificasen con fondos propios de dicho crédito para pago de obligaciones ordinarias, y por último las existencias disponibles como diferencia de los ingresos y gastos ${ }^{14}$.

13 Tan pronto como se conociese la cantidad invertida se procedería a legalizar la concesión instruyéndose el oportuno expediente con sujeción a lo establecido por la ley de contabilidad para las provincias ultramarinas, Archivo del Consejo de Estado, U-019-016, Consulta elevada el dos de septiembre sobre el expediente del crédito extraordinario.

14 Estas cuentas de la Intendencia, una vez que puedan localizarse, permitirán completar la Cuenta de la Campaña de Filipinas que se llevaba en el Ministerio de Ultramar y en la que no se registraban los ingresos que realizados en las Filipinas también fueron destinados a la guerra. Para el caso cubano sí hemos podido disponer de esta documentación. Consúltese Inés RoldAN DE MONTAUD, "España y Cuba. Cien años de relaciones financieras”, Stvdia Historia. Historia Contemporánea, vol. 15, 1997, pp. 60 y ss. 


\title{
CUADro I
}

LA CUENTA DE LA CAMPAÑA DE FILIPINAS DEL 24 OCTUBRE DE 1896 AL 3 DE JUNIO DE 1898 (PESOS)

\author{
INGRESOS \\ Producto de 200.000 obligaciones hipotecarias serie A de 100 pesos \\ nominales suscritas al 92 por 100 \\ Negociación de 106.252 de dicha clase (adquiridas por el His- \\ pano Colonial en en noviembre y diciembre de 1897 y enero y \\ febrero 1898* \\ Beneficios en la acuñación de moneda de plata y giros \\ Cantidades destinadas transitoriamente de los fondos destinados \\ a la campaña de Cuba
}

Pagos

Pagos al ramo de Guerra

Pagos al ramo de Marina

Giros de la Intendencia de Hacienda

Remesas en metálico a las cajas de Filipinas

6.000 .000

Ingresado en efectivo en Manila por giros cablegráficos

1.562 .450

Aplicado en Filipinas al fondo de campaña por pagos hechos en Madrid

Pagos al Ministerio de Estado

Intereses quebrantos de giros y gastos varios

2.161 .833

21.340

Importe de lo pagado por gastos de campaña

19.891 .800

\section{Pagos por otros conceptos}

Diferencia entre las cantidades anticipadas para el pago de la campaña de Cuba y lo reintegrado por cuenta de dichos anticipos

Reintegro de las cantidades tomadas transitoriamente de los fondos destinados a la campaña de Cuba

FUENTE: Gaceta de Madrid, núm. 293, 20 de octubre de 1898. La Gaceta proporciona información detallada sobre todos los ingresos y gastos de la cuenta.

* Incluye las 50.000 obligaciones retenidas inicialmente de la Serie A, y las 50.000 retenidas de la serie B, así como las obligaciones de la serie B que no pudieron ser colocadas en el mercado Filipino (véase más adelante). 
Sabemos pues que el Tesoro filipino recurrió en los primeros momentos a la emisión de deuda flotante, por lo demás prevista en su presupuesto vigente. Hasta octubre el intendente de Hacienda de Filipinas, José Gutiérrez de la Vega, salió adelante mediante préstamos del Banco Español de Filipinas y mediante anticipos tomados seguramente de la Caja de Depósitos y de los Fondos Locales ${ }^{15}$. El Banco se había constituido en 1855 y era el único banco privilegiado de emisión de la colonia. Con antelación había prestado servicios financieros al Tesoro local. En febrero de 1896 había logrado que se le prorrogase su privilegio de emisión por 25 años, contrayendo el compromiso de ampliar su capital hasta 1.500 .000 pesos en $1902^{16}$. La Junta general del 4 de mayo de aquel año decidió realizar una primera ampliación de 300.000 pesos emitiendo en junio 1.500 acciones. Se había pensado que la ampliación del capital fuese realizándose paulatinamente. Sin embargo, al iniciarse la guerra la demanda de crédito tanto del sector público como privado aumentó y en Junta general de accionistas a mediados de noviembre de 1897 quedó aprobada una nueva ampliación del capital social por importe de 600.000 pesos, elevando el capital hasta 1.500.000. Así podía disponer de recursos para atender la mayor demanda de crédito surgida a raíz de la insurrección ${ }^{17}$. El aumento del capital permitía al establecimiento aumentar la cantidad de billetes en circulación para atender las exigencias de la intendencia.

Con toda seguridad la intendencia estaba encontrando dificultades para lograr estos anticipos y era urgente dotar el crédito establecido con cargo al artículo adicional de los capítulos de Guerra y Ma-

15 Colección Legislativa de España, tomo CLX. vol. 2, 1896, pp. 837-838. La Real orden de 19 de diciembre dictaba reglas de contabilidad para las operaciones de deuda flotante de Tesoro de Filipinas con el Banco Español, los Fondos Locales y otras instituciones, ibíd, pp. 890-891.

16 Revista Mercantil, núm. 1.143, 30 de marzo de 1896 y el Comercio del 19 de marzo de 1896. Se autorizaba al Banco a aumentar el capital hasta 3.000 .000 de pesos a medida que lo necesitase siempre y cuando no tocase su fondo social. Podría emitir billetes por el triple de su capital efectivo conservando en caja el equivalente a la cuarta parte de las obligaciones a la vista (depósitos, cuentas corrientes y billetes en circulación). En compensación tendría que prestar gratuitamente hasta 500.000 pesos, o la tercera parte de su capital cuando fuese superior a 1.500 .000 pesos, durante seis meses al año, el resto de sus prestamos los realizaría a un 1.5 por 100 menos que el descuento corriente que hiciese el público.

17 El Comercio, 21 de noviembre de 1896 y 2 de febrero de 1897. El Real decreto de Castellanos de 28 de junio de 1897 se hacía eco de los préstamos del Banco "que aumentó su capital con este motivo" Colección Legislativa de España, tomo CLXI, 1897, vol. 1, p. 314. 
rina de recursos efectivos. El gobierno optó entonces por ir pagando los gastos de la campaña de Filipinas con recursos procedentes de los fondos que se habían obtenido para la Campaña de Cuba mediante una serie de operaciones de crédito autorizadas por las Cortes en marzo y junio de 1895 . Primeramente se habían vendido y pignorado títulos de la deuda del Tesoro de Cuba, los billetes hipotecarios creados en 1890. Más tarde, una vez consumidos los recursos así proporcionados, las Cortes había aprobado la realización de un empréstito interior realizado en el otoño de 1896 por un importe de 400 millones de pesetas nominales ${ }^{18}$.

Es probable que la decisión de anticipar recursos del Tesoro de Cuba se adoptara bien entrado el mes de octubre. Las Cuentas de la Campaña de Filipinas registran estas transferencias de fondos de la campaña de Cuba a partir del día 24 (cuadro 1). Entre octubre de 1896 y agosto de 1897 los anticipos ascendieron a 7.660 .403 pesos (algo más de 38 millones de pesetas). A partir de entonces, como veremos, la realización de una operación de crédito a cargo del Tesoro de Filipinas permitió a éste disponer de recursos propios, cesando las transferencias de la cuenta de Cuba. ¿Cómo se gastaron estos recursos? Sabemos que de dicha cantidad 1.2 millones fueron entregados directamente en Madrid a la Compañía Trasatlántica para el pago del transporte de tropas ${ }^{19}$. En Madrid se hacían también pagos al ramo de Guerra y Marina. Se situaron en Londres 100.000 libras esterlinas (600.000 pesos) para que la Intendencia filipina pudiese girar sobre ellas. Dada la situación de los cambios estos giros produjeron en Manila más de un millón de pesos ${ }^{20}$. Se giraban también letras de la Intendencia de Hacienda a cargo del ministerio de Ultramar. Las listas de todo el material de guerra y provisiones pagadas de este modo pueden encontrase publicadas en las Cuentas de la Campaña y no pueden sino ser mencionadas aquí. Finalmente se remitió directamente metálico a las cajas de Filipinas.

\footnotetext{
18 Elena HeRnÁNDEZ SANDOICA y María Fernanda MANCEBo [3], 1980. pp. 157-68.

19 Gaceta de Madrid, núm. 63, 4 de mazo de 1897, Cuenta de la Campaña de Cuba, p. 968. y núm 266, 23 de septiembre de 1997, Cuenta de la Campaña de Cuba, p. 1.271. y Gaceta de Madrid, núm. 293, 20 de octubre de 1898, Cuenta de la Campaña de Filipinas, p. 305.

20 El Comercio, 14 de abril de 1894, "Correspondencia".
}

R. I., $1998, \mathrm{n}^{\circ} 213$ 


\section{LA CUESTION DE LA PLATA Y LA GUERRA EN FILIPINAS}

Efectivamente, era preciso también poner a disposición de las autoridades económicas en Manila recursos para realizar ciertos pagos in situ. En un intento de hacer frente a la tirantez monetaria que la guerra acentuó, mediado el mes de abril el Consejo de Ministros ordenó a la Casa de Moneda de Madrid que preparase la acuñación de dos millones de pesos plata. La Real orden del 17 dispuso la creación de una moneda especial de un peso para Filipinas, de ley, cuño y peso idénticos al de las monedas de cinco pesetas que circulaban en la península, sin más distintivo que la siguiente leyenda en el reverso: "Islas Filipinas, un peso". Se garantizaba así que su circulación quedase limitada al archipiélago donde tendría plena eficacia liberatoria desde que fuese publicado en la Gaceta del Manila la Real orden que lo creaba ${ }^{21}$.

Conforme a las Cuentas de la Campaña de Filipinas, a lo largo de la guerra se remitieron por mediación del Banco de España un total de 6.000.000 de pesos plata ${ }^{22}$. Los primeros dos millones fueron remitidos el 6 de mayo. Otros tantos se enviaban el día 22. El 17 de junio se remitía una nueva partida de dos millones. Esta plata permitía a la intendencia hacer frente a los pagos diarios que debían realizarse en el propio archipiélago filipino, pagos a abastecedores locales de todo género, y fundamentalmente, pago de los haberes de los 25.000 soldados que en pocos meses España había colocado en Filipinas. El estallido de la guerra y el aumento consiguiente de la demanda de numerario habían obligado, finalmente, al gabinete de Madrid a tomar una decisión en materia monetaria que, desde luego, no ponía término al grave problema monetario cuya solución venía aplazándose desde hacía años.

Filipinas, lo mismo que Puerto Rico, venía atravesando trastornos monetarios serísimos desde la década de los setenta, que habían sido objeto de un crecido número de opúsculos e innumerables artículos de prensa en los que se analizaba una y otra vez la cuestión y

21 Colección Legislativa de España, tomo CLXI, vol. 1, 1897, p. 578. La Vanguardia 13 de marzo de 1897, p. 5 y La política de España en Filipinas. Quincenario defensor de los intereses españoles en las colonias del extremo oriente, año VII, núm. 154, p. 124 "El duro filipino", 15 de marzo 97

22 Gaceta de Madrid, núm. 293, 20 de octubre de 1898, Cuenta de la Campaña de Filipinas, p. 308. 
se discutían las soluciones ${ }^{23}$. En 1876 una desacertada medida en política monetaria había abierto el mercado a la moneda de plata mexicana declarándola moneda legal con fuerza liberatoria junto a la de cuño nacional. Los 35 ó 40 millones de pesos oro de cuño nacional que circulaban en Filipinas desplazados por la plata emigraron con rapidez, produciéndose un envilecimiento de la circulación. En un intento de corregir la situación en 1877 se prohibió la introducción de plata mexicana, de modo que a partir de aquella época el peso mexicano fue introducido fraudulentamente y sujeto a falsificaciones continuas y difíciles de detectar. Consumado el desagüe del oro comenzaron a sentirse oscilaciones violentas en los cambios. En el 1894 las letras sobre la península llegaron al 65 por 100 de perdida. Sin deuda externa, con el dinero a una tasa de interés normal, con presupuestos nivelados, experimentando el comercio un crecimiento y con una balanza comercial favorable, la causa no podía ser otra que la depreciación de la moneda empleada en los cambios, la perdida de valor de la plata ${ }^{24}$. Se produjo entonces un amplio movimiento de opinión que veía la solución al problema en la modificación del sistema monetario filipino. Había que volver a dotar a las colonias orientales de una moneda fija y estable que permitiera la inmigración de capitales, el crecimiento económico y el aumento del consumo. Se exigía la recogida del peso mexicano y su sustitución por plata nacional, si bien lo deseable era el regreso a una circula-

\footnotetext{
23 A modo de introducción al problema entre otros títulos pueden consultarse: Evaristo ROMERO Y PEREZ, Informe sobre el estado de los cambios por, Manila, Imprenta de la Revista Mercantil, 1896; La cuestión monetaria y de los cambios en Filipinas. Solución de la Cámara de Comercio. Exposición al Ministro de Ultramar, Madrid, Imprenta de la Viuda de Minuesa (s.a.); Francisco Godinez, Ponencia presentada a la Comisión gestora del canje de la moneda mexicana en Filipinas, Madrid, Establecimiento Tipográfico Fortanet, 1894; Historia económica de España en Filipinas. Una ponencia inédita sobre la cuestión monetaria, Manila, Imprenta Litográfica Partier, 1900.

24 Cuando el oro era la base del sistema monetario los cambios con el extranjero variaban en un 5 ó 6 por 100 de beneficio o quebranto, según la ley de la oferta y demanda.

Filipinas debía pagar en oro sus deudas con el extranjero y se veía obligada a comprar letras en oro y a abonar la diferencia entre la depreciada moneda de plata única de la que disponía y la libra esterlina. Para pagar la diferencia tenía que entregar plata por su valor intrínseco, ya que la moneda de plata no tenía fuerza liberatoria en Londres. Estos trastornos monetarios eran compartidos por los países exportadores cuyo sistema monetario se basaba en una plata que perdía valor, La política de España en Filipinas, 15 de septiembre de 1897, p. 412, "La cuestión monetaria".
} 
ción bimetálica representado el oro por billetes de banco garantizados por una reserva en dicho metal.

El ministerio dejó pasar el tiempo sin adoptar una resolución y llegó la guerra. Entonces presionado por las necesidades del momento y seguramente sin buscar una solución definitiva para el problema monetario filipino que permitiera nivelar los cambios optó como señalábamos más arriba - por el monometalismo plata, creando el nuevo signo de cambio -el peso plata para Filipinas-. Los efectos de la política adoptada no tardaron en dejarse sentir. Los cambios que en el mes de marzo de 1897 se situaban en torno al 32 por 100, en junio de 1897 habían subido al 61 por 100. Con la subida de los cambios la vida se hacía imposible en Filipinas para los funcionarios y clases civiles y militares que vivían de un sueldo del Estado y en general para los consumidores. La situación monetaria afectó de inmediato al comercio, que incapaz de hacer frente a los pagos anulaba los pedidos. Estos trastornos monetarios afectaron sin duda a los exportadores peninsulares que veían aumentar el precio de sus productos en la misma proporción en que subían los cambios. Al mismo tiempo el margen protector que en el arancel filipino se había establecido para preservar aquel mercado a la industria peninsular perdía su eficacia frente a los productos procedentes del extranjero de países en los que habían adoptado el patrón oro.

Al abrigo del irresuelto problema monetario crecía el descontento que añadía un elemento más al malestar y perturbación causados por la guerra. Todavía en el otoño de 1897 se oían voces que clamaban por una solución al problema de los cambios. En plena guerra, con un déficit instalado sobre el presupuesto ya no era posible pensar en un empréstito ${ }^{25}$ que permitiera adquirir oro para implantar el patrón oro como había propuesto en 1894 la Junta de Comercio de Manila. Ya sólo era posible - indicaban quienes exigían que el gobierno hiciese algo- un arreglo parcial que pasaba por una nivelación de los cambios con la península. Para ello debían dejarse de imprimir pesos filipinos, admitirse éstos en la península con pleno valor liberatorio y realizarse las sucesivas remesas en duros peninsulares. Finalmente debía canjearse el peso mexicano por el na-

\footnotetext{
25 Se acababa de realizar una gran operación de crédito para obtener dinero para la guerra de Filipinas, cuyo estudio abordamos más tarde.
} 
cional prohibiendo la circulación de aquél en Filipinas ${ }^{26}$. No era una solución definitiva que se adoptaría cuando concluida la guerra se procediera al arreglo de la Hacienda filipina. La propuesta no fue tenida en cuenta. Si muchos sectores sufrían gravemente los efectos de los cambios elevados, otros resultaban beneficiados por el statu quo. La propia Hacienda derivaba beneficios de la acuñación y envío de plata a Filipinas (cuadro 1) en la misma proporción en que se sufría quebranto o pérdida en los giros realizados desde Filipinas.

\section{LA CREACION DE LA DEUDA FILIPINA: LOS BILLETES HIPOTECARIOS DEL TESORO DE FILIPINAS}

En marzo de 1897 la guerra parecía adquirir mayor gravedad, y a principios de mes el general Polavieja pedía el envío de 20.000 hombres más. El empleo de fondos destinados a la campaña de Cuba sólo podía ser un expediente transitorio, por lo demás de cuestionable legalidad, en tanto se lograba disponer de recursos propios para la campaña de Filipinas, más si se tiene en cuenta que también los fondos para la guerra de Cuba mermaban rápidamente y que los millones obtenidos mediante la colocación del gran empréstito interior con garantía de las aduanas españolas realizado en el otoño del 96 prácticamente se había consumido.

Mientras se reunían las Cortes y se aprobaban las leyes que permitirían al gobierno seguir procurándose dinero para la guerra en Cuba, en la primavera del año 1897 el gobierno hacía gestiones con banqueros extranjeros y nacionales para obtener un empréstito para Filipinas. Desde fines de 1896 la prensa madrileña se refería a una operación de crédito para el Tesoro de Filipinas que cifraba en torno a diez millones. Nada había de preciso en aquellos rumores. Se hablaba de un empréstito especial amortizable; más tarde de un préstamo del Banco de España sobre el cual giraría la intendencia en Manila. Habrían de pasar todavía muchos meses hasta el verano de 1897 para que quedase perfilada la operación que desde el principio parecía imprescindible.

El 20 de abril Pedro de Sotolongo, el director del Banco Hispano-Colonial, llegaba a Madrid. Se iniciaban entonces negociaciones

26 La política de España en Filipinas, núm. 171, 15 de octubre de 1897, p. 447.

R. I., 1998, n. 213 
con el grupo Comillas y con otras casas de Barcelona para que realizasen un empréstito de 200 millones al 7 por 100 con garantía de la renta de aduanas de Filipinas, amortizable en 40 años. Las negociaciones saltaron a la prensa durante el mes de mayo. Ya el día 28 los periódicos madrileños se ocupaban de las dificultades que la directiva del Banco Hispano Colonial había opuesto a la propuesta que llevaba Sotolongo ${ }^{27}$. Las negociaciones fueron un fracaso. Los banqueros catalanes rechazaron el negocio, pese a que el tipo de interés ofrecido era muy elevado. Unicamente se comprometerían a realizar una operación semejante en caso de obtener la garantía adicional de la nación, y ésta únicamente podían concederla las Cortes ${ }^{28}$. Como la necesidad de normalizar la situación del Tesoro Filipino era urgente, en un intento de allanar el camino se llegó a discutir incluso la posibilidad de que fuese el Consejo de Estado el que acordase la garantía exigida por los banqueros ${ }^{29}$.

Sin concurso del capital privado, consumidos los recursos producidos por el empréstito interior, el gobierno decidió recurrir nuevamente al Banco de España que en abril se comprometía a realizar nuevos anticipos mediante el descuento de pagarés del Ministerio de Ultramar garantizados mediante la ampliación en 200 millones de las obligaciones sobre la renta de aduanas creadas en el otoño de 1896. Antes de votarse la autorización abriría créditos al gobierno para las islas Filipinas en los mismos términos en que había hecho sus adelantos al Tesoro cubano, pero - advertía al ejecutivo- para poder hacerlo tendría que aumentar sus emisiones.

Abiertas las Cortes el 20 de mayo de 1897, el ministro de Ultramar Tomás Castellano presentaba un proyecto de ley en el que se autorizaba al gobierno para conceder la garantía general de la nación a las operaciones de crédito que se realizasen por cuenta del Tesoro de Filipinas para hacer frente a las gastos ocasionados por la alteración del orden público que no pudiesen satisfacerse mediante recursos ordinarios ${ }^{30}$. En breve, el proyecto se aprobaba sin discusión y se

27 El Comercio, 24 de mayo de 1897, "El correo".

28 Rothschild Archive London, XI/59/2A, 22 de abril 1897. The Economist, 15 de mayo de 1897, p. 712. El Economista, 2 de mayo de 1897, p. 319.

29 Rothschild Archive London, XI/59/2A/, Ignacio Baüer a los Rothschild, 22 de abril 1897.

30 Diario de Sesiones del Congresos de los Diputados, apéndice 2 al núm. 102, 25 de mayo de 1897.

R. I., 1998, n. $^{\circ} 213$ 
convertía en ley el 10 de junio de 1897 . La concesión de la garantía de la nación con carácter general para las deudas de los Tesoros coloniales no era una novedad. Se había planteado sin éxito allá por el año 1872; había sido exigida por los banqueros que anticiparon en el año 1876 dinero para la guerra de Cuba, en una operación que daba origen al Banco Hispano Colonial; de dicha garantía habían disfrutado también las deudas del Tesoro de Cuba creadas en 1880, 1882, 1886 y 1890, y sin ella no podría realizarse con éxito ninguna operación de crédito por cuenta del Tesoro Filipino.

Inmediatamente después comenzó a hacerse uso de la autorización. Los reales decretos firmados por Tomás Castellano el 28 de junio fijaron las condiciones de la emisión de 400.000 obligaciones hipotecarias del Tesoro de Filipinas por valor de 200 millones de pesetas nominales con garantía de las rentas de las Filipinas y la general de la nación. En el preámbulo el ministro justificaba el empréstito recordando los gastos extraordinarios que había traído la guerra sobre el Tesoro de Filipinas, así como los daños que la misma estaba ocasionando sobre las rentas públicas haciéndolas disminuir. Si inicialmente los préstamos del Banco Español y otras instituciones habían permitido hacer frente a los gastos, la magnitud de los mismos era tal que, aseguraba el ministro: "excedían los medios disponibles por las entidades bancarias y demás Centros financieros de aquel Archipiélago". La operación tenía como finalidad devolver el orden a aquella Hacienda. Los billetes hipotecarios se amortizarían en 40 años, disfrutarían de un interés del 6 por 100, serían considerados como efectos públicos y estarían exentos de cualquier tipo de impuesto hasta su amortización.

La emisión se dividió en dos series: la serie A que se pagaría en Madrid, Barcelona y demás plazas del reino estaba compuesta por 250.000 billetes de 500 pesetas ( 125.000 .000 de pesetas), de los cuales, de momento, se ofrecían al público únicamente 200.000. Los otros 50.000 quedarían a disposición del Ministerio de Ultramar para hacer frente a ulteriores necesidades en el marco de la ley de 10 de julio. Los recursos obtenidos se emplearían para devolver las cantidades anticipadas por el Ministro de Ultramar de los fondos obtenidos para la guerra de Cuba, así como las adelantadas por el Tesoro de la península en forma de suministros, equipo y transporte de los 25.000 soldados y más de 2.500 marinos enviados al archipiélago a lo largo de aquel invierno. La serie B que se pagaría en

R. I., $1998, \mathrm{n}^{\circ} 213$ 
pesos en Manila estaba constituida por 150.000 obligaciones de 100 pesos (15.000.000 de pesos o 75.000 .000 de pesetas), de las cuales se ofrecerían al mercado 100.000 , quedando otras 50.000 a disposición del ministro. Los recursos obtenidos se emplearían para devolver al tipo de emisión del 92 por 100 los adelantos hechos al Tesoro de Filipinas por firmas y bancos locales, entre ellos el Banco Español Filipino, y otros establecimientos, y para hacer frente a la deuda flotante creada en el Archipiélago y al déficit que ofreciese el presupuesto de 1896-97.

El ministro debió de albergar dudas sobre el éxito del empréstito. Un fracaso en su colocación podía ser la señal para la caída de los valores públicos en un mercado ya sobrecargado. Se habían colocado ya entre el público billetes hipotecarios de la isla de Cuba y obligaciones sobre la renta de aduanas por importe de 400 millones. Por otra parte, la cotización de todos los valores públicos se había resentido desde el inicio de la guerra. De ahí la serie de medidas adoptadas para garantizar el éxito de la nueva operación financiera, tales como la de fijar el tipo de emisión en un 92 por 100 del valor nominal (inferior al tipo al que en aquel momento se cotizaban los billetes hipotecarios de Cuba un 96 por 100, e inferior también al tipo al que el año anterior se habían colocado las obligaciones de aduanas). Esta condición suponía claramente un aumento del interés real sobre el legalmente establecido en el decreto de creación de la nueva deuda, que la hacía todavía más atractiva.

Por otra parte, para asegurar el éxito de la operación el gobierno contrató la colocación de los 200.000 títulos que se ofrecían al público de la serie A con el Banco Hispano Colonial y un sindicato de banqueros españoles. Este sindicato asegurador garantizaba al Tesoro la suscripción total mediante una comisión del $21 / 2$ por 100 del valor nominal de los títulos y del 1/2 por 100 para el Hispano Colonial $^{31}$. Las condiciones en que fue colocado el empréstito fueron pues peores que las establecidas para el de 1896, que se había colocado sin gasto de comisiones y al 93 por 100. El empréstito de Fili-

31 Dicha comisión ascendía según la partida correspondiente de la Cuenta General de la Campaña a 600.000 pesos. Además se abonaría a los establecimientos que abriesen la suscripción pública 0.25 por 100 sobre el importe efectivo de los títulos que adjudicasen. J. M. JIMÉNEZ y RODRíGUEZ, Estudio crítico de la crisis monetaria, Madrid, 1905, p. 183, La banca española en la Restauración, [3], p. 347 y The Economist, 24 de julio de 1897, p. 1057. 
pinas fue, sin duda, más caro que el realizado en 1896 para obtener dinero para la guerra de Cuba.

La necesidad de revestir al empréstito de tantas precauciones fue muy discutidas entonces. Se consideró que habían sido excesivas, no sólo dada la pequeña dimensión del empréstito, sino fundamentalmente porque sobre el Tesoro de las islas Filipinas - a diferencia del de Cuba - no pesaba deuda alguna. Su resultado demostró que a pesar de las operaciones de crédito realizadas en esos años, existían todavía recursos suficientes y tal vez, como sugería El Economista que el tipo de emisión adoptado había sido bajo en demasía ${ }^{32}$.

El servicio de esta deuda quedó encomendado al Banco Hispano Colonial. Los orígenes del Banco estaban vinculados al empréstito cubano de 1876, y con posterioridad el establecimiento había estado interesado en diversas operaciones financieras de Ultramar, participando en la negociación de la deuda de Cuba en 1880, 1886 y nuevamente en 1890. El Hispano Colonial quedaba encargado de los intereses y amortización de la deuda del Tesoro de Filipinas mediante una comisión de 2.5 por 100 de la anualidad para la serie A y 3.5 para la B. Corrían por cuenta del Gobierno los gastos de confección de los títulos y las carpetas provisionales y los gastos de concentración de fondos en Manila o el extranjero. El Banco recaudaría con los empleados del Gobierno la renta de aduanas de Filipinas y retendría diariamente la cantidad de dinero necesaria para que dos meses antes de la fecha de vencimiento del cupón de la serie A pudiese tener reunida en Manila la cantidad suficiente para hacer frente a intereses y amortización y para sufragar los gastos correspondientes al costo de cambio y traslación de dichos fondos a Europa. Cada día retendría también el dinero necesario para disponer en Manila el día 20 del último mes de cada trimestre de la cantidad precisa para el pago del cupón de la serie B. Sin que exista todavía una investigación concluyente, probablemente fueron las ganancias derivadas de esta negociación lo que permitió al Hispano Colonial aumentar sus beneficios en el año 1897. Su cuenta de ganancias pasó de dos millones de pesetas en 1896 a 3.5 en $1897^{33}$.

\footnotetext{
32 El Economista, año 1898, p. 446.

33 Pedro TEDdE, La Banca Española en la Restauración. Política y finanzas [3], p. 347.
}

R. I., 1998, $\mathrm{n}^{\circ} 213$ 


\section{LOS RESULTADOS DEL EMPRESTITO EN LA PENINSULA Y EN FILIPINAS}

Uno de los reales decretos expedidos por el ministro de Ultramar el 28 de junio abría la suscripción de las 200.000 obligaciones de la serie A que tuvo lugar el 15 de julio. El empréstito se cubrió más de cinco veces, ascendiendo las suscripciones a 1.044.519 títulos, 844.519 más que los ofertados. Sólo en Madrid el público suscribió 441.501, en Barcelona 244.19834.

Conforme a los cálculos realizados en el Anuario de la Bolsa el Tesoro de Filipinas obtuvo por los 100 millones emitidos 86.863.904, es decir que el tipo de emisión real había sido el 86.8 por 100. La anualidad necesaria para amortizar los 100 millones sería de 6.610 .070 pesetas. A esta cifra debía agregarse el 2.5 por 100 que para gastos establecía el decreto de 28 de julio resultando 6.775.322. De modo que por un capital de 86 millones de pesetas el Tesoro filipino debía devolver en cuarenta años algo más de $271^{35}$. Las condiciones financieras del empréstito fueron pues, como indicábamos más arriba, mucho peores para la Hacienda que las del realizado nueve meses antes.

El éxito de la operación volvía a sorprender en Europa, como había sorprendido el del empréstito de obligaciones sobre la renta de aduanas del otoño de 1896: "Parece que hay mucho dinero en el país para que se puedan emitir a la vez un gran empréstito para Filipinas y obligaciones del Tesoro por cuenta del Banco", indicaba uno de los Rothschild ${ }^{36}$. Sin duda el resultado de la operación produjo una mejora en la cotización de los valores españoles en el extranjero ${ }^{37}$. El primero de agosto quedaba admitida la contratación e incluidas en la cotización oficial, como efectos públicos, las carpetas provisionales

34 Banco Hispano Colonial. Memoria leída en la Junta general extraordinaria de accionistas del 8 de enero de 1897, Barcelona, 1897, p. 6. Más detalles sobre la emisión en Anuario de la Bolsa del Comercio y de la Banca para 1898, año VII, pp. 308-316. Entre los mayores suscriptores de Madrid figuraban: el Crédit Lyonnais 62.000 títulos; Manuel G. Longoria 52.000; los Sres. Sainz e hijos 17.000; Juan José Escanciano 10.000; Antonio Velázquez Duro 7.600; Marqués de Casa Jiménez 7.000. La Epoca, 16 de julio de 1897.

35 Anuario de la Bolsa del Comercio y de la Banca para el año 1898, vol. VII, p. 315. Los cálculos coincidían con los datos aportados por La política de España en Filipinas, núm. 172,31 de octubre de 1897 , p. 485

36 Rothschild Archive London, XI/101/36, Rothschild Freres a Rothschild and Sons, 19 de julio de 1897.

37 La Época, 18 de julio de 1897. 


\section{CUADRO 2}

SUSCRIPCCION DEL EMPRESTITO DE FILIPINAS SERIE A POR PROVINCIAS

\begin{tabular}{|c|c|c|c|}
\hline & Suscriptores & Obligaciones & $\begin{array}{l}\text { Valor nominal } \\
\text { (pesetas) }\end{array}$ \\
\hline Madrid & 3.040 & 446.501 & 223.250 .500 \\
\hline Barcelona & 1.107 & 244.198 & 122.099 .000 \\
\hline Bilbao & 1.682 & 138.513 & 69.256 .500 \\
\hline Zaragoza & 1.126 & 53.896 & 26.947 .500 \\
\hline Santander & 429 & 25.009 & 12.504 .500 \\
\hline Valencia & 330 & 12.600 & 6.300 .000 \\
\hline Coruña & 233 & 12.300 & 6.150 .000 \\
\hline Sevilla & 145 & 12.000 & 6.000 .000 \\
\hline S. Sebastián & 201 & 10.050 & 5.025 .000 \\
\hline Pamplona & 164 & 10.028 & 5.014 .000 \\
\hline Málaga & 70 & 9.417 & 4.708 .500 \\
\hline Valencia & 199 & 8.116 & 4.058 .000 \\
\hline Burgos & 282 & 6.000 & 3.000 .000 \\
\hline Valladolid & 204 & 5.735 & 2.867 .500 \\
\hline Gijón & 81 & 4.500 & 2.250 .000 \\
\hline Vigo & 167 & 4.165 & 2.082 .500 \\
\hline Córdoba & 66 & 4.000 & 2.000 .000 \\
\hline Cádiz & 148 & 3.886 & 1.943 .000 \\
\hline Jerez & 41 & 3.354 & 1.677 .000 \\
\hline Alicante & 92 & 3.068 & 1.534 .000 \\
\hline Palencia & 72 & 2.975 & 1.487 .500 \\
\hline Reus & 61 & 2.961 & 1.480 .500 \\
\hline Granada & 163 & 2.411 & 1.205 .500 \\
\hline Salamanca & 154 & 2.400 & 1.200 .000 \\
\hline Murcia & 102 & 2.000 & 1.000 .000 \\
\hline Palma & 93 & 1.823 & 911.500 \\
\hline Toledo & 578 & 1.325 & 662.500 \\
\hline Guadalajara & 170 & 1.250 & 625.000 \\
\hline León & 60 & 1.000 & 500.000 \\
\hline Orense & 62 & 863 & 431.500 \\
\hline Gerona & 57 & 818 & 409.000 \\
\hline Tarragona & 60 & 787 & 393.500 \\
\hline V. y Geltrú & 39 & 740 & 370.000 \\
\hline Teruel & 31 & 664 & 332.000 \\
\hline Cartagena & 27 & 572 & 286.000 \\
\hline Mahón & 42 & 552 & 276.000 \\
\hline Lérida & 26 & 400 & 200.000 \\
\hline Segovia & 26 & 251 & 125.500 \\
\hline Almería & 4 & 59 & 29.500 \\
\hline TOTAL: & 11.740 & 1.051 .187 & 525.593 .500 \\
\hline
\end{tabular}

FUENTE: Anuario de la Bolsa del Comercio y de la Banca para 1898, año VII, p. 312.

R. I., 1998, n. $^{\circ} 213$ 
sionales de las obligaciones hipotecarias del Tesoro de Filipinas de la serie $\mathrm{A}^{38}$.

La colocación de las obligaciones hipotecarias del Tesoro de Filipinas no encontró tanta facilidad en el archipiélago. A ello contribuyó, sin duda, por un parte, el hecho de que se trataba de una operación sin precedentes en el archipiélago, donde se desconocían las ventajas y la naturaleza del crédito público y el beneficio que representaba la inversión de capitales en valores del Estado. Era la primera vez, exclamaba $\mathrm{El}$ Comercio, que el crédito público entraba en la vida económica de aquella tierra ${ }^{39}$. Es probable, incluso, que las dos únicas y limitadas experiencias que los filipinos habían tenido en el terreno del crédito público, más bien actuaran como un elemento disuasorio: la primera se remontaba a la década de los 70 y había consistido en la entrega a los cosecheros de tabaco de unas papeletas en lugar del dinero que debían percibir al contado por el tabaco que se les obligaba a cultivar y a vender al Estado (recuérdese que el tabaco era objeto de monopolio por parte del Estado). Durante años estas papeletas no se pagaron, hasta que en 1876 fueron recogidas y canjeados por unos títulos creados entonces los billetes del Tesoro de Filipinas con una pérdida del 20 por 100 del capital ${ }^{40}$. La otra experiencia había sido el establecimiento en Manila de una Caja de Depósitos, cuyos impositores habían visto suspenderse la devolución de los capitales depositados por falta de recursos, lo cual había herido, sin duda, el crédito público en Filipinas.

Por otra parte, la situación económica iba empeorando y comenzaban a sentirse los efectos de la insurrección, que afectaba, desde luego, a los cambios haciéndolos subir a 61 por 100 en julio. El malestar comenzaba a extenderse incluso en medios peninsulares donde cundía la idea de que en el estado de cosas existente influía el comportamiento del Banco Español de Filipinas, contra el cual se le-

\footnotetext{
38 Real orden de 17 de julio de 1897 del Ministerio de Fomento a la Junta Sindical de Agentes de Cambio y Bolsa. El 23 de julio el ministro de Ultramar daba traslado de la misma a Cuba y Filipinas, Colección Legislativa de España, tomo CLXII, vol. 2, 1897, pp. 99-100. A fines de junio de 1898 se mandó cotizar también las obligaciones de la serie B gran parte de las cuales se habían domiciliado ya en la península, Colección Legislativa de España, 1898, vol. I, pp . 598-99.

39 El comercio, 30 de julio de 1896.

40 La política de España en Filipinas, año VII, núm. 160, 30 de abril de 1897, p. 202. A esta operación de crédito nos hemos referido más arriba.
} 
vantaba la opinión pública acusándolo de importar plata mexicana y retener en sus cajas sustrayéndolas de la circulación las nuevas monedas filipinas ${ }^{41}$. Y es que inicialmente se había albergado confianza en que la afluencia de nueva moneda de plata mejoraría los cambios, ilusión que no tardaba en desvanecerse. Era en estas circunstancias, en un país asolado por la insurrección, donde el gobierno hacía el llamamiento al crédito público.

A lo largo del mes de julio se fueron remitiéndose a Filipinas las instrucciones para preparar el empréstito previsto en el Real decreto de 18 de junio. Finalmente, la Real orden de 25 Julio hacía públicas las condiciones en que se colocaría la serie B y el 15 de agosto se abría en Manila la suscripción mediante un decreto del gobernador Primo de Rivera ${ }^{42}$. Para intentar garantizar el éxito de la operación en un país ajeno a ese tipo de prácticas, de geografía compleja y población dispersa, tuvo que rodearse el empréstito de condiciones especiales. El plazo de suscripción que en la península había sido de un día se extendía en Filipinas desde el 15 de agosto hasta el 15 de septiembre. Por otra parte, el gobierno había decidido admitir, considerándolas como metálico real y efectivo para la suscripción de las obligaciones, las cartas de pago de imposiciones realizadas en la Caja de Depósitos, estuviesen o no vencidas junto al interés devengado. Ponía así término al conflicto que representaba la suspensión de la devolución de los ahorros de quienes los habían depositado voluntariamente en la Caja. Era, tal vez, requisito imprescindible para levantar el crédito y cubrir la operación.

La intendencia de Hacienda en Manila se encargaría de la suscripción de aquéllos títulos que no fuesen pagados en metálico sino mediante cartas de pago sobre imposiciones de la Caja de Depósitos y otros créditos contra el Tesoro. El Banco Español de Filipinas y la Compañía de Tabacos de Filipinas se encargarían de realizar los títulos que fuesen pagados en metálico, cada uno en una serie de provincias. Ambos podrían nombrar delegados en los diversos puntos o bien autorizar a los gobernadores civiles y militares para que aceptasen su representación.

Las facilidades dadas fueron insuficientes. Pese a que el período de suscripción que en principio acababa el 15 de septiembre fue

\footnotetext{
41 La Vanguardia, 17 de julio de 1897.

42 Gaceta de Manila, núm. 228, 16 de agosto de 1897, p. 969.
}

R. I., $1998, \mathrm{n}^{\circ} 213$ 
prolongado hasta finales de mes y a otras facilidades concedidas a la serie $\mathrm{B}$, de las 100.000 obligaciones ofertadas al público por un importe de 50 millones de pesetas se suscribieron 91.100 títulos por importe de 45.550 .000 pesetas. Quedaron por suscribir algo más de 6.252 títulos $^{43}$. A juicio de algún observador como el corresponsal del Diario de Barcelona en Manila, el resultado de la operación no se debía a la falta de confianza, era simplemente el fruto de la pobreza del país ${ }^{44}$. Debe recordarse, por otra parte, que las condiciones del cambio con la metrópoli hacían imposible la inversión de capitales excedentes en la península, porque la amortización y pago de intereses se realizaban en Manila en plata depreciada y su repatriación se hubiese realizado con una pérdida del 60 por 100 . La misma que sufrían los funcionarios y militares al trasladarse a la península con sus ahorros o la que sufrían las clases pasivas que en la península cobraban sus haberes con cargo a la Caja de Manila.

El escaso éxito de la serie B cobra mayor relieve si se tiene presente que más de 5.5 millones de pesos de los obtenidos procedían del canje de créditos que ya existían contra el Tesoro. Los impositores de la Caja de Depósitos se apresuraron a convertir sus títulos por un importe de 5.411 .833 pesos más unos intereses de 119.180 , un total de 5.531.013 pesos. La razón hay que buscarla en el tipo de interés generado por los nuevos títulos, muy superior al 5 por 100 que devengaban las imposiciones en la Caja. Entre los grandes impositores que convirtieron sus créditos figuraban el Banco Español por 70.000 pesos y los menores de Manuel Pérez Samanillo por 220.000 pesos, Manuel Velasco por 289.000, Inchausti y Cía. por 100.000, el director del Monte de Piedad por más de 264.000 pesos y la Compañía General de Tabacos por $9.000^{45}$.

En la provincia de Manila se suscribieron 11.873 obligaciones. Entre los mayores suscriptores figuraban: el Banco Español de Filipinas - que acababa de ampliar su capital social y disponía de recursos- con 3.212 obligaciones; el obispo de Cebú con 2.020; la Corporación Dominicana con 1.110, el arzobispo de Manila con otros 1.000; el procurador General de San Francisco 600; Fray Feli-

43 Colección Legislativa de España, 1898, p. 87. Anuario de la Bolsa del Comercio y la Industria para el año 1898 , vol. VII, p. 311.

44 Diario de Barcelona, edición de la tarde, 19 de agosto de 1897.

45 La lista completa en Gaceta de Manila, núms. 297 y ss. 
pe García 500; la Real Casa de Misericordia 447; Procurador G. de Recoletos 300; la Compañía de Jesús 200; el Casino Español 200. Seguían en orden de importancia algunos particulares como Felipe García 500, Victoriano G. Palazuelo 400, Manuel Baez 240, y algunas casas comerciales como Aldecoa y Cía. 210, Luengo Hermanos 211, Inchausti y Cía 137, Findlay y Cía 66, el Banco de Hong-Kong 65, o el Chartered Bank 5246. La Compañía General de Tabacos únicamente suscribía 46 títulos. De un total de 289 suscriptores en la provincia de Manila únicamente 21 lo fueron por 100 títulos o más, en torno a 170 por uno o dos títulos. Estos pequeños impositores eran casi sin excepcion de origen chino, grupo de población afincado en algunos puntos de Filipinas y especialmente en Manila dedicado esencialmente a las actividades de carácter comercial.

Si nos fijamos con detenimiento en el resultado del empréstito en las provincias de mayor número de suscriptores, después de Manila, Batangas y Pangasinam encontramos también la existencia de muchos pequeños suscriptores por muy escaso número de títulos. En Batangas hubo una suscripción de 500 títulos de la casa Aldecoa y Cía. Hubo tres suscriptores por 50 títulos entre ellos la Junta Provincial; diez entre 10 y 49 títulos. El resto de los suscriptores - 380suscribió 10 o menos títulos, abundando los suscriptores de un solo título. El caso de Pangasinam fue similar. La gran subscriptora fue, como en muchas otras provincias, la Junta Provincial por 166 títulos. Entre 15 y 55 títulos hubo cinco suscriptores, 8 entre 11 y 15 , y el resto suscribió un único título.

La negociación de las filipinas (así se llamaron aquellos valores) procuró dinero para proseguir la guerra en el Pacífico, permitió devolver los anticipos tomados de los fondos para la campaña de Cuba, y permitió igualmente acudir temporalmente en ayuda del Tesoro cubano. A lo largo del mes de agosto de 1897 fueron devueltos los siete millones anticipados y desde septiembre de 1897 hasta abril de 1898 se anticiparon para la guerra de Cuba por la Cuenta de la Campaña de Filipinas más de 13 millones de pesos ${ }^{47}$.

Apremiado por las necesidades financieras el ministro de $\mathrm{Ha}-$ cienda del recien creado gabinete liberal comenzaba a adoptar medidas. Disponía de los títulos que no se habían ofertado al público y

46 Gaceta de Manila, núm. 300, 29 de octubre de 1897, p. 1250 y ss.
47 Gaceta de Madrid, núm. 266, 22 de septiembre de 1897, p. 1271.

R. I., $1998, \mathrm{n}^{\circ} 213$ 
que habían quedado en cartera del Ministerio de Ultramar, 50.000 de cada una de las series, y de los que no se habían suscrito en Filipinas, unos 6.000. Era impensable que los títulos de la serie B pudiesen ser colocados en el mercado en Manila donde un par de meses antes había fracasado el empréstito. Era necesario colocar el resto de la serie B en España, donde los saldos de las cuentas corrientes demostraban que había dinero. Pero había que transformar las condiciones de los títulos de la serie $\mathrm{B}$, de modo que fueran aceptables en el mercado de capitales de la metrópoli. Para resolver el problema la Real orden de 8 de febrero permitió domiciliar en la península la amortización e intereses de los títulos de la serie $\mathrm{B}$, que se pagarían en las mismas condiciones que la serie $\mathrm{A}$, es decir se les concedía condiciones idénticas a la serie $\mathrm{A}$, recibiendo el nombre de obligaciones hipotecarias igualadas ${ }^{48}$. Dos días después el Banco Hispano Colonial tomaba las 56.252 obligaciones restantes de la serie B al 93 por 100. Unos meses antes (noviembre y diciembre) había adquirido en condiciones muy ventajosas a un tipo del 90 por $100^{49}$ las 50.000 de la serie A que no habían sido ofrecidas al mercado en el momento de la emisión.

Tras la creación de la deuda del Tesoro de Filipinas era necesario disponer de una institución donde los tenedores de fondos públicos pudiesen realizar sus operaciones y a la que acudiesen comerciantes y propietarios para realizar las transacciones de frutos y mercancías. El Real decreto de 13 de Julio dispuso la creación en Manila de una Bolsa-Lonja Oficial de Comercio para la contratación de efectos públicos y comerciales en la ciudad de Manila. Los gastos de establecimiento y funcionamiento correrían por cuenta de los presupuestos de Fondos Locales ${ }^{50}$.

48 Real orden de 8 de febrero firmada por Segismundo Moret, Colección Legislativa de España, 1898, vol. I, pp. 86-87. Dicha decisión aumentaba los gastos necesarios para la situación de fondos en la península, pero proporcionaba al Tesoro de Filipinas una cantidad mayor que la que hubiese podido realizar con la negociación de las obligaciones de la serie B a causa de los beneficios que se obtenían en los cambios de la península con las Filipinas, compensándose el aumento de los gastos.

49 Ibíd., Real decreto de 8 de febrero 1898, Gaceta de Madrid, 21 de febrero de 1900, Cuentas de la Campaña de Filipinas, en Gaceta de Madrid, núm. 293, 20 de octubre, p. 305. y V. FERNÁNDEZ ACHA, Datos básicos para la historia financiera de España 18501975, Instituto de Estudios Fiscales, 1976, vol. II, pp. 48 y 49. de 1897.

50 Colección Legislativa de España, tomo CLXII, 1897, vol. 2, pp. 20-21, 13 de julio 
La existencia de la guerra en Filipinas y la creación de la nueva deuda perturbaron la marcha equilibrada de su Hacienda. Poco antes de iniciarse la insurrección, el Real decreto del 21 de agosto aprobaba el presupuesto para el ejercicio de 1896-97. En él se habían reforzado notablemente los ingresos mediante la creación de un impuesto de descarga de un dos por 100 sobre el valor de las mercancías de toda clase y procedencia. Se había establecido además un impuesto sobre el consumo de una serie de productos que se haría efectivo en las aduanas y regiría desde la publicación en la Gaceta ${ }^{51}$. El Real decreto de 25 de junio de 1897 prorrogó este presupuesto para el ejercicio 1897-98, con las modificaciones acordadas después, entre otras la autorización del crédito extraordinario concedido el 18 de septiembre y mencionado en otro lugar de estas páginas ${ }^{52}$. La creación de deuda del Tesoro de Filipinas el 28 de junio iba a ocasionar un aumento considerable en la partida de Obligaciones Generales del presupuesto ordinario que no podía ya ni siquiera hacer frente a los gastos ordinarios debido a la disminución de los ingresos por efecto de la guerra. El servicio de la nueva deuda requería algo más de tres millones de pesos anuales, y uno más por quebranto o daño producido al situar los fondos en la península dado que los cambios pasaban del 60 por 100 .

Creada la obligación el ejecutivo no tenía más remedio que dotar al presupuesto de nuevos ingresos. Una vez realizado el empréstito en España y abierta la suscripción en Filipinas, el Real decreto del 14 de agosto establecía un recargo de un 6 por 100 sobre el valor oficial de las mercancías importadas en las islas, con independencia de su procedencia, y autorizaba la redención a metálico de los quince días de prestaciones personales que se seguían exigiendo a la población indígena como contribución heredada de la época de la conquista y que había sido objeto de sucesivas reducciones ${ }^{53}$.

Hasta que no dispongamos de las liquidaciones presupuestarias practicadas por la Intervención General del Estado en Filipinas no estaremos en condiciones de conocer el resultado de los presupuestos ordinarios del archipiélago, la forma en que la guerra afectó a la

51 Entre los que figuraban los aguardientes de todas clases, cervezas, legumbres y hortalizas secas, harinas de trigo, petróleo y aceites minerales, que variaba de unos productos a otros, Revista Mercantil, núm. 1154, 2 de septiembre de 1896.

52 Gaceta de Manila, núm. 180, 10 de julio de 1897, p. 765.

53 La Vanguardia del 21 de agosto de 1897.

R. I., $1998, \mathrm{n}^{\circ} 213$ 
recaudación existente, la medida en que estos nuevos impuestos fueron capaces de cubrir los nuevos compromisos que la guerra arrojó sobre la colonia, y la cuantía del déficit con el que, sin duda, cerraron los presupuestos ordinarios del período de la guerra. En cuanto a los gastos extraordinarios irían cargándose al capítulo adicional abierto en las secciones de guerra y marina que se nutrió inicialmente con transferencias de dinero obtenido para la guerra de Cuba, más tarde con el producto de la serie A del empréstito y a fines del año 1897 y principios de 1898 con el producto de la venta de los títulos de la serie A reservados y los de la serie B igualados.

Los recursos obtenidos mediante la serie B en Filipinas, que no debieron de llegar a ocho millones de pesos (unos 91.000 títulos de 100 pesos al 90 por 100) no aparecen contabilizados entre los ingresos de la Cuenta de la Campaña de Filipinas que se llevaba en el Ministerio de Ultramar desde octubre de 1896 (cuadro 1). Debieron de figurar en la Cuenta Corriente del Tesoro Público de Filipinas que debía llevarse en las dependencias de Hacienda de Filipinas conforme a las previsiones de la Real orden del 18 de diciembre que comentábamos más arriba. Allí figurarían entre los ingresos junto a las remesas enviadas desde Madrid, los giros, la venta de letras a cargo del Ministro, y, sin duda, junto al producto de los donativos y suscripciones públicas realizadas en Filipinas, o los anticipos que hicieran instituciones como el Banco Español ${ }^{54}$. Por tanto, para saber cuánto costó la guerra habría que añadir a lo gastado conforme a la Cuenta de la Campaña de Filipinas del Ministerio lo gastado en Filipinas de recursos obtenidos en el archipiélago, que, en cualquier caso no debió de ser de gran magnitud. Desestimando estas cantidades y atendiendo únicamente a la Cuenta de la Campaña la guerra de Filipinas costó entre octubre de 1896 y 3 de junio de 189838.490 .680 pesos (cuadro 1). Entre julio y diciembre de dicho año se gastaron otros 7.029.629 pesos ${ }^{55}$. Entre 1 de enero y 30 de junio de 1899 los gastos ascendieron a 3.885 .966 pesos $^{56}$. Entre 1 de julio y $31 \mathrm{de} \mathrm{di-}$ ciembre de 1899 se gastaron otros 2.280 .375 pesos. Entre 1 de enero de 1900 y 31 de diciembre de 1902 en que desaparece la Cuenta el

\footnotetext{
54 Para el caso cubano sí hemos podido disponer de esta documentación, lo que nos permitió establecer con precisión el funcionamiento de la doble contabilidad durante la guerra, Inés ROLDAN DE MONTAUD [14], pp. 61 y ss.

55 Gaceta de Madrid, núm. 52, 21 de febrero de 1899, p. 677.

56 Gaceta de Madrid, núm. 263. 20 de septiembre de 1899, p. 1075.
} 
importe de lo gastado ascendía a 2.598.920. En total entre octubre de 1896 y diciembre de 190251.686 .680 pesos.

\section{EL TRATADO DE PARIS Y LA DEUDA FILIPINA}

Durante las negociaciones que condujeron a la firma del tratado de París los comisionados plantearon la cuestión de las deudas coloniales. Desde un principio España había pensado hacer recaer aquellas deudas sobre los Tesoros coloniales, y sus delegados en París insistieron en que tanto la deuda de Cuba como la de Filipinas debían ser consideradas como deudas locales. Ante la posición de los Estados Unidos España acabaría asumiendo la responsabilidad de las deudas de sus antiguas colonias, pese a que en términos estrictamente jurídicos no estaba obligada a ello ${ }^{57}$. Se descartaba así la tesis del simple repudio que se había abierto camino en amplios sectores de opinión.

A partir de marzo de 1899 el ministro de finanzas del nuevo gabinete conservador, Raimundo Fernández Villaverde, comenzaba a adoptar una serie de medidas necesarias para liquidar la guerra, entre otras el reconocimiento de las deudas coloniales. El decreto de $10 \mathrm{de}$ abril de 1899 concedía un crédito extraordinario con aplicación al presupuesto filipino para el ejercicio 1898-99 para el pago de intereses y amortización de los billetes hipotecarios (3.300.000 pesetas) que se cubriría con los recursos extraordinarios para la campaña de Filipinas ${ }^{58}$. En el mes de diciembre su predecesor había adoptado una medida similar para el pago de los intereses de las deudas de Cuba, pero había dejado en suspenso la amortización de los títulos del Tesoro cubano. A partir de estas disposiciones la subrrogación por España de las deudas coloniales era un hecho.

De derecho ésta se produjo con la Ley de 2 de agosto de 1899. En ella encontramos ya un reconocimiento categórico de las deudas

\footnotetext{
57 Una extensa discusión sobre las deudas coloniales y el Tratado de París en Inés ROLDAN DE MONTAUD [3], pp. 656-664.

58 Gaceta de Madrid, 12 de abril de 1899, p. 127. Villaverde mantuvo la amortización de las filipinas y frente a quienes le reprochaban el trato desigual del que eran objeto ambas deudas, el ministro sostenía como justificación que la deuda de Filipinas se había creado únicamente para atender la campaña, la de Cuba había sido creada mucho antes de la guerra y sólo en parte se había dedicado a financiarla.

R.I., 1998, n. $^{\circ} 213$
} 
coloniales. En la sección de Obligaciones Generales del presupuesto quedaría abierto un capítulo, deudas procedentes de las Colonias, con crédito suficiente para el pago de los intereses. El total de las deudas procedentes de las colonias ascendía en 1899 a 2.695 pesetas, cuyo servicio exigía 197 millones. Las deudas del Tesoro filipino ascendían a 198.3 millones de pesetas que exigían 13.3 millones anuales. El presupuesto General del Estado en modo alguno podría soportar tal carga. La subrogación de las deudas coloniales sólo era posible, por tanto, si se procedía a una completa reordenación de la deuda pública del Estado y si se imponía un sacrificio para los portadores de la deuda. Así, la mencionada Ley de 2 de agosto, dispuso la reducción en un 20 por 100 (10 por 100 en el caso de Filipinas) del importe de los cupones de las deudas coloniales en concepto de asimilación a las nacionales, suprimiendo el mayor interés que siempre habían disfrutado las deudas ultramarinas por razón de su mayor riesgo. Villaverde lograba también limitar la carga financiera de la deuda suspendiendo definitivamente la amortización de los billetes hipotecarios de Cuba y Filipinas ${ }^{59}$. Con estas y otra serie de medidas que afectaban a las deuda general del Estado lograba reducir los gastos de la Deuda hasta hacerlos compatibles con los recursos del Estado que se veían también afectados por una profunda reforma tributaria. Aceptada la subrrogación con las mencionadas limitaciones, la transformación efectiva de las deudas coloniales en nacionales se produjo en 1900 cuando los billetes hipotecarios de Filipinas (lo mismo que los de Cuba) quedaron convertidos en deuda interior amortizable al 4 por 100.

After a brief outlook at the financial situation of the Philippine Islands before the outbreak of the colonial war in the summer of 1896, this article analyzes the financial policies followed by the spanish government in order to produce extraordinary means for the war. Special attention is given to the monetary problems of the Philippines and to the financial operation that took place in the summer of 1897, originating the Philippine Treasury Debt, and to the way in which Philippine debt was dealt with after the Treaty of Paris.

59 Ibidem, p. 287. Sobre el arreglo de la deuda véase Gabriel SolE VillalongA, La reforma fiscal de Villaverde, 1899-1900, Madrid, Derecho Financiero, 1967. 